\title{
Development of Quality Indicators to Assess Oral Anticoagulant Management in Community Pharmacies for Patients with Atrial Fibrillation
}

\author{
Mylène Chartrand, BPharm; Line Guénette, BPharm, PhD; Denis Brouillette, BPharm, DPH; \\ Stéphane Côté, BPharm, DPC; Roger Huot, MD, FRCPC; Jérôme Landry, BPharm; \\ Josée Martineau, BPharm, MSc, BCPS; Sylvie Perreault, BPharm, PhD; \\ Brian White-Guay, MD, CCMF, FRCPC; David Williamson, BPharm, PhD, BCPS; \\ Élisabeth Martin, MSc; Marie-Mireille Gagnon, MSc; and Lyne Lalonde, BPharm, PhD
}

\begin{abstract}
BACKGROUND: Few studies have evaluated the quality of oral anticoagulant management by community pharmacists. There is no complete set of quality indicators available for this purpose.

OBJECTIVE: To develop a set of specific quality indicators to assess oral anticoagulant management by community pharmacists for patients with atrial fibrillation (AF).

METHODS: Quality indicators were developed in 3 phases. In phase 1, potential quality indicators were generated based on clinical guidelines and a literature review. In phase 2, a modified RAND appropriateness method involving 2 rounds was implemented with 9 experts, who judged the appropriateness of quality indicators generated in phase 1 based on the extent to which they were accurate, based on evidence, relevant, representative of best practices, and measurable in community pharmacies. Phase 3 consisted of a feasibility assessment in 5 community pharmacies on 2 patients each.
\end{abstract}

RESULTS: The final set included 38 quality indicators grouped into 6 categories: documentation $(n=29)$, risk assessment $(n=3)$, clinical control $(n=1)$, clinical follow-up $(n=15)$, choice of therapy $(n=11)$, and interaction management $(n=8)$. The quality indicators referred to process of care $(n=34)$, clinical outcomes $(n=2)$, or structure of care $(n=2)$. There were 24 quality indicators related to vitamin $\mathrm{K}$ antagonists (VKAs), and 17 were related to direct oral anticoagulants (DOACs). To assess quality indicators, a questionnaire was developed for completion by community pharmacists for each patient, which included 17 questions about VKA patients and 12 questions about DOAC patients.

CONCLUSIONS: A first set of quality indicators is now available to assess the quality of oral anticoagulant management by community pharmacists for patients with AF.

J Manag Care Spec Pharm. 2018;24(4):357-65

Copyright @ 2018, Academy of Managed Care Pharmacy. All rights reserved.

\section{What is already known about this subject}

Quality indicators are useful to assess the quality of care.

- Little is known about the quality of oral anticoagulant management by community pharmacists.

\section{What this study adds}

This study provides a first set of quality indicators to assess oral anticoagulant (vitamin $\mathrm{K}$ antagonists and direct oral anticoagulants) management for patients with atrial fibrillation in a community pharmacy setting.

These indicators were based on a modified systematic appropriateness approach.

These quality indicators can be assessed using a brief questionnaire, with a proposed scoring method.

A trial fibrillation (AF), the most prevalent arrhythmia, affects $1 \%-2 \%$ of the general population, with higher prevalence in the older population. ${ }^{1}$ For these patients, the risk of stroke is up to 5 times greater than for patients without AF, leading to increased risk of death and disability. ${ }^{2}$ Anticoagulant agents considerably reduce morbidity and mortality in AF patients. ${ }^{3,4}$ Guidelines recommend vitamin $\mathrm{K}$ antagonists (VKAs) and direct oral anticoagulants (DOACs) for the prevention of stroke and thromboembolic events for the majority of AF patients. ${ }^{5-7}$ However, VKAs are associated with an overall incidence of major bleeding in approximately 2 per 100 patient-years. ${ }^{8}$ In randomized controlled trials, DOACs are similar to or more effective than VKAs in terms of efficacy and rates of major bleeding. ${ }^{4}$ However, the generalizability of these results in real-world conditions remains to be demonstrated. Close monitoring is needed to achieve adequate anticoagulation while avoiding bleeding complications.

In recent years, community pharmacists have become more involved in oral anticoagulation management. In a 2013 survey in Quebec, Canada, 45\% of community pharmacies reported offering such services. ${ }^{9}$ Few studies have evaluated the quality of oral anticoagulant management by community pharmacists. Most such studies had small sample sizes and focused mainly on VKAs and international normalized ratio (INR) control, with limited data on other management aspects. ${ }^{10-17}$ One study of DOACs evaluated the effect of pharmacists' audits on improving the quality of dabigatran prescriptions. ${ }^{18}$ 
Quality indicators are developed to assess quality of care and are defined as "a measurable element of practice performance for which there is evidence or consensus that it can be used to assess the quality, and hence change in the quality, of care provided."19 Quality indicators relate to structure (characteristics of service providers), process (steps in providing care), outcome (effect of care on health status), and security (occurrence of adverse events) of care. ${ }^{19-24}$ To our knowledge, there is no complete set of quality indicators available to assess oral anticoagulant management by community pharmacists. Most quality indicators are related to VKAs and are not specific to community pharmacy. ${ }^{25-46}$ Those indicators related to DOACs essentially pertain to treatment adherence. ${ }^{34}$ Recently, other measures regarding DOAC appropriateness criteria for prescriptions were developed for inpatients and ambulant patients. ${ }^{18,46,47}$ Finally, quality indicators for pharmaceutical care are not specific to anticoagulation management. ${ }^{48-50}$

The objective of this study was to develop a complete set of quality indicators to assess the management of oral anticoagulants (VKAs and DOACs) by community pharmacists for AF patients.

\section{Methods}

In 2014, this study was conducted in 3 phases. In phase 1, an initial list of quality indicators was developed mostly based on Canadian clinical guidelines and a literature review. In phase 2 , nine experts took part in a modified systematic approach based on consensus techniques (i.e., a modified RAND/University of California, Los Angeles (UCLA) Appropriateness Method) to assess the appropriateness of each quality indicator and to add to the list if needed. ${ }^{51}$ In phase 3 , a feasibility assessment was conducted in community pharmacies. This study was approved by the research ethics board of the University of Montreal Hospital Research Center. Experts involved in phase 2 and pharmacists involved in phase 3 received no monetary compensation for their participation.

\section{Phase 1}

An extensive literature review was conducted in PubMed and Embase to search for existing quality indicators. Key words related to atrial fibrillation and anticoagulants were used to search the clinical categories. To identify studies linked to quality indicators, keywords such as quality indicator*, performance indicator*, quality measure*, performance measure*, and benchmark* and MeSH terms such as quality assurance, health care and outcome and process assessment (health care) were added to the search strategy. The search was limited to studies published in English or French between 2000 and 2014. A grey literature search using the Google search engine and a review of references of relevant articles were also completed. Some quality indicator/measure repositories were consulted, such as the National Quality Measures Clearinghouse (http://www. qualitymeasures.ahrq.gov/) and the Pharmacy Quality Alliance (http://pqaalliance.org/measures/default.asp), as well as websites of major organizations with a known interest in evaluating the quality of AF care. Database searches were done under the guidance of an information specialist. The research team then generated an initial set of potential quality indicators based mostly on Canadian clinical guidelines in force at the time of the study, 5,52 along with selected quality indicators suggested by other initiatives..$^{25-37,42-45,47,53-55}$ Quality indicators were kept if they could be adapted to anticoagulation management in community pharmacy in terms of efficacy, safety, and treatment adherence.

\section{Phase 2}

A panel of 9 experts participated in a modified RAND/UCLA Appropriateness Method exercise ${ }^{51}: 2$ community pharmacists, 3 hospital pharmacists working in pharmacist-managed anticoagulation clinics or with expertise in cardiovascular diseases, 2 primary care physicians, 1 cardiologist, and 1 researcher. The appropriateness surveys were conducted in 2 rounds.

In the first round, a self-administered questionnaire was e-mailed to each expert. For each quality indicator obtained in phase 1, a summary of evidence-based information was provided. The experts were instructed to rate the appropriateness of each quality indicator considering the evidence-based information provided by the research team and their clinical judgment. Certain criteria were specified: quality indicators should be accurate, evidence-based, relevant, representative of best practices, and measurable in community pharmacies. ${ }^{20}$ Instructions were also given to the experts regarding some restrictions to ensure the feasibility of applying quality indicators in a quality improvement program: no information could be collected directly from patients; quality indicators should be assessed based on data collected through a questionnaire completed by pharmacy staff using data available in their pharmacy records; and time required to complete the questionnaire should be short.

The appropriateness of each quality indicator was rated on a Likert scale from 1 (totally inappropriate) to 9 (totally appropriate). The median score was computed. The experts had the opportunity to suggest modifications or additional quality indicators. At the end, quality indicators with a median appropriateness score of $\geq 7$ without disagreement were kept, while those with a score of $\leq 3$ without disagreement were discarded. Disagreement was considered to exist when the median score was $\geq 7$ with at least 3 ratings (33\% of the experts) of $\leq 3$ or when the median score was $\leq 3$ with at least 3 ratings (33\% of the experts) of $\geq 7$.

The second survey round was an in-person group meeting where members could express their opinions and discuss proposals for modifying, adding, or scoring quality indicators. Panelists received the modified quality indicator list along with their scores, median scores, disagreements, and an abstract of panel members' comments. They rated the appropriateness of each quality indicator with a median score between 4 and 6 , as well as those with disagreements. They also rated new or 
modified quality indicators. After discussion, a vote was taken. Only quality indicators with a median score of $\geq 7$ without disagreement were kept for the final list.

\section{Phase 3}

To document all information needed to assess each quality indicator, a questionnaire was developed by the research team and further improved with the collaboration of 5 community pharmacists working in different pharmacies (available in French on request). Each of these pharmacists then completed the questionnaire twice, in relation to 2 of their anticoagulated AF patients, without identifying the patients. The research team used this information to assess each quality indicator. Quality indicators that could not be assessed were discarded. Minor changes were made to some quality indicators, which were then submitted by e-mail to the 9 experts for approval.

After phase 3, the research team classified the final quality indicators into 6 categories: documentation, risk assessment, clinical control, clinical follow-up, choice of therapy, and interaction management. Because documentation could apply to several categories, all quality indicators in the documentation category were classified in another category. As such, categories were not mutually exclusive. Quality indicators were also classified in another category according to whether they pertained to VKAs or DOACs and were categorized according to their main type: structure, process, outcome, or security.

Finally, a computerized program to assess each quality indicator was developed using SPSS Statistics software, version 19.0 (IBM, Armonk, NY) and SAS software, version 9.2 (SAS Institute, Cary, NC). Briefly, for each patient, a quality indicator score could be assessed as "1" (management is concordant with quality indicator), "0" (management is not concordant with quality indicator), or "not applicable" (the quality indicator does not apply). For example, for patients taking DOACs, it is recommended to document their renal function at least annually. The quality indicator was scored as "l" if this was done and documented in the pharmacy record, as " 0 " if it was not done or not documented, or as "not applicable" if the patient was on VKA. If a quality indicator could be assessed more than once during the follow-up, a mean score was computed, which could vary between 0 (never done or documented) and 1 (always done and documented). For example, it is recommended to notify the prescriber each time an INR $<1.8$ is observed in a patient on VKA. So, if INRs $<1.8$ were observed on 2 occasions, but the prescriber was notified only once, then the quality indicator score would be $0.5([1+0] / 2)$. Then, for each pharmacy, we were able to compute the mean percentage of quality indicators achieved for each applicable category of quality indicators and for the entire set of applicable quality indicators (number of applicable quality indicators achieved divided by number of applicable quality indicators).

\section{Results}

The development of the quality indicators is summarized in Figure 1. In phase 1, thirty-eight quality indicators were developed to assess efficacy, safety, and treatment adherence in relation to oral anticoagulant management by community pharmacists.

In phase 2, after the first round of the appropriateness survey, 17 of the 38 initial quality indicators were judged uncertain or were modified by the experts to improve comprehensiveness, feasibility, and/or accuracy. They suggested adding 8 quality indicators to assess other important aspects of therapy management (e.g., education, dose adjustment based on renal function, and combination of antiplatelet drugs). In the second round, 25 quality indicators were assessed, of which 4 were judged inappropriate.

In phase 3, the research team developed a questionnaire with 17 questions regarding VKA patients and 12 questions regarding DOAC patients to document information for the assessment of each quality indicator (available in French on request). Questions were multiple choice or short answer. Quality indicators were applied to 10 patients from 5 pharmacies based on the information collected. Seven quality indicators were discarded for the following reasons: (a) could not be assessed using questionnaire information (would require full drug history instead of a questionnaire, $\mathrm{n}=1$ ); (b) duplication between quality indicators ( $\mathrm{n}=1$ ); and/or (c) information rarely available in the pharmacy record (e.g., hospitalization, $n=5$ ). Seven quality indicators were modified, and 3 were added to better match guideline recommendations or improve comprehensiveness, feasibility, and accuracy. Modifications were sent to and accepted by the expert panel.

The final set of 38 quality indicators covered documentation $(n=29)$, risk assessment $(n=3)$, clinical control $(n=1)$, clinical follow-up ( $n=15)$, choice of therapy $(n=11)$, and interaction management $(n=8)$. These indicators related to process of care $(n=34)$, clinical outcomes $(n=2)$, or structure of care $(n=2)$. Overall, 24 indicators applied to VKAs, and 17 quality indicators were related to DOACs (Table 1).

\section{Discussion}

Given that community pharmacists play an important role in oral anticoagulant management for AF patients, it is essential to evaluate the quality of their care in relation to different aspects of therapy management and, if needed, propose appropriate quality improvement programs. We have developed a set of quality indicators specifically designed to assess the quality of oral anticoagulant management in the community pharmacy setting. These quality indicators were developed using a modified systematic appropriateness approach combining evidence with consensus. They can be assessed using a brief questionnaire, and a scoring method is proposed.

Most of our quality indicators relate to the care process (34 of 38), which is key information for quality 


\section{FIGURE 1 Development of Anticoagulation Quality Indicators for Community Pharmacies Using a Modified} RAND/UCLA Appropriateness Method

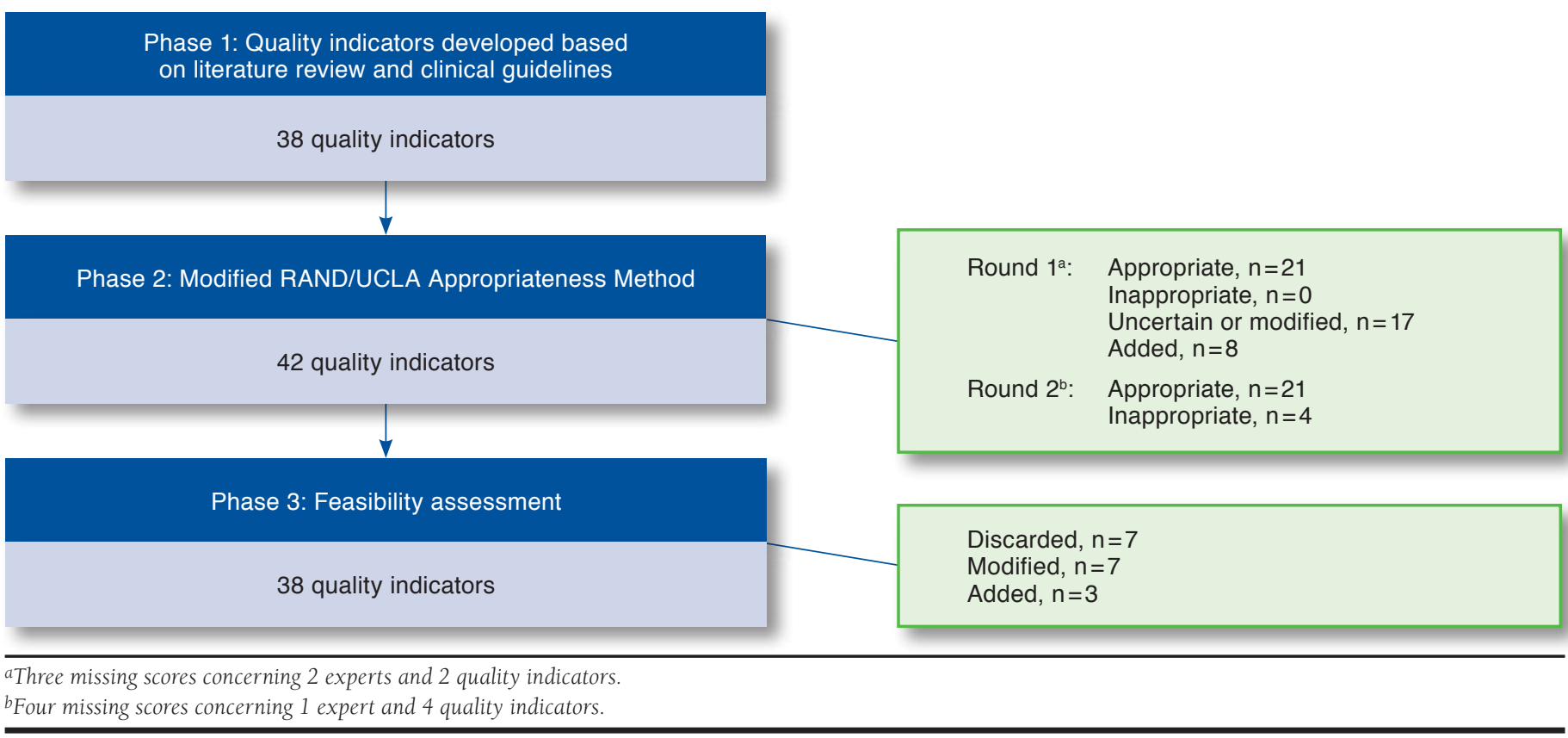

assessment, since these indicators appraise what a pharmacist did for a patient and how it was done. ${ }^{21-24}$ These quality indicators are easier to interpret in a short time frame and are more sensitive to changes. Among the 34 process quality indicators, the majority $(\mathrm{n}=29)$ are related to documentation. As with any measurement effort, it is not possible to distinguish between what is not done and what is not documented, so these indicators may underestimate the quality of care. On the other hand, according to current practice standards, appropriate documentation in pharmacy records is under the liability of pharmacists. Documentation is important for therapy management and care continuity. However, it is known that clinical documentation of patient care in community pharmacies is challenging and limited. ${ }^{56-58}$ Record system formats vary across pharmacies, with some designed to document and support optimal pharmaceutical care while others are not. Access by community pharmacists to clinical data may also vary, which would influence quality indicator scores. A 2014 pan-Canadian (excluding Quebec and the territories) survey of community pharmacies reported the benefits in productivity and quality of care with electronic health records deployed by provinces and territories. ${ }^{59}$ In Quebec, electronic health records are gradually being implemented and allow pharmacists, for example, to access data on laboratory values, such as creatinine levels, thereby enabling pharmacists to estimate and document renal function. An international study showed that most experts stress the importance of information technology to document, access, and share information to support the development of community pharmacy services. ${ }^{60}$

Quality indicators targeting clinical outcomes (2 of 38) are also important, since they represent an end result of care. ${ }^{19-24}$ Ideally, quality indicators should be linked to desirable health outcomes for patients. In our quality indicators, time in therapeutic range (TTR) for patients on VKAs is well accepted as an important intermediate outcome and a predictor of bleeding and thromboembolic events. ${ }^{61}$ This indicator is in line with the current literature evaluating the quality of community pharmacy-based anticoagulation management services. ${ }^{11,12,16}$ With regard to patients using DOACs, adherence to treatment is an essential aspect of treatment, considering their pharmacokinetic profiles. Adherence is used to evaluate clinical and economic outcomes. ${ }^{62}$

Structural quality indicators are those related to pharmacy characteristics and organization of pharmaceutical care. ${ }^{19-24}$ In our set, 2 quality indicators belong to this category: availability of a validated nomogram for dosage adjustment and quality control tests of the portable device to measure INRs. In general, there is limited evidence of a relationship between structure and outcomes. However, we can reasonably assume that good structure tends to result in good process. ${ }^{19,22,23}$ In 


\section{TABLE 1 Quality Indicators for Anticoagulation Therapy Management in Community Pharmacies}

Indicators

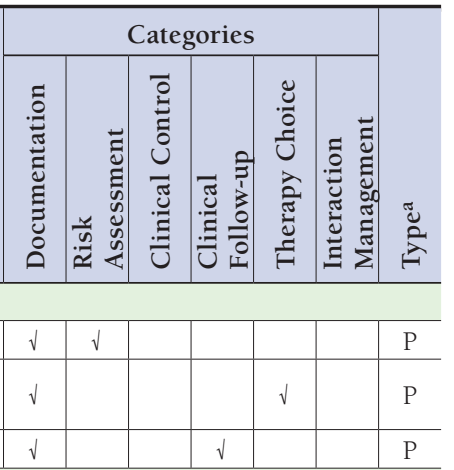

All oral anticoagulant therapy

Documentation of thromboembolic risk $\left(\mathrm{CHADS}_{2}\right.$ or $\mathrm{CHA}_{2} \mathrm{DS}_{2}$ VASc score)

Documentation of confirmation of the bi- or tri-therapy initiation (anticoagulant with antiplatelets) with the prescriber (except if prescribed by the same physician on the same prescription)

Documentation of patient anticoagulation therapy education done at the beginning and during treatment

Vitamin K antagonist

Documentation of bleeding risk (HAS-BLED score or other (e.g., HEMORR2HAGES, Landefeld index) ${ }^{\mathrm{b}}$

Documentation of modification or no modification in smoking status in the past 6 months

Documentation of change or no change in alcohol consumption in the past 6 months

Documentation of reconfirmation of the target INR with prescriber when patient initiates one or more antiplatelets

External quality control procedure of the portable coagulometer is done by pharmacist at least twice a year if this device is used for anticoagulated patients

Availability of a validated nomogram for dosage adjustment reported by pharmacist

Documentation of patient's natural health products consumption

Documentation of patient's over-the-counter drugs consumption

Patient's target range of INR is appropriate according to patient's indication ${ }^{c}$

Documentation that prescriber has been notified at the latest 7 days following an INR $<1.8$

Documentation that prescriber has been notified at the latest 7 days following an INR $>5$

Documentation of the pharmacist's intervention at the latest 7 days following 3 consecutive nontherapeutic INRs for patients taking VKA for more than 6 months

TTR $\geq 60 \%$ for patients taking VKA for more than 6 months

A new INR is available at the latest 7 days after a patient's nontherapeutic INR ${ }^{c}$

A new INR is available at the latest 14 days after a patient's moderately nontherapeutic INRc

A new INR is available at the latest 28 days after a patient's slightly nontherapeutic INRc

A new INR is available at the latest 6 weeks after a patient's therapeutic INRc

Documentation that the prescriber has been notified when a patient is no longer a customer of the pharmacy or is lost to follow-up

Documentation of pharmacist's intervention to find a probable cause when TTR is $<60 \%$

Documentation of pharmacist's intervention to suggest/verify possibility of switching VKA to DOAC when TTR is $<60 \%$ without reason

Documentation of pharmacist's intervention to add LMWH when INR is $<1.8$ and thrombotic risk is important $\left(\mathrm{CHADS}_{2}>3\right.$, mechanical heart valve)

\section{Direct oral anticoagulant}

Documentation of patient's eClcr minimally once a year

Documentation of pharmacist's intervention with prescriber to suggest/verify possibility of decreasing dabigatran dosage to $110 \mathrm{mg}$ BID if one of these factors is present: weight $<50 \mathrm{~kg}$, age $\geq 80$, or eClcr between $30-49 \mathrm{~mL} / \mathrm{min}$

Documentation of pharmacist's intervention with prescriber to suggest decreasing apixaban dosage to

$2.5 \mathrm{mg}$ BID when eClcr is between $30-49 \mathrm{~mL} / \mathrm{min}$ and age $\geq 80$ or weight $\leq 60 \mathrm{~kg}$

Documentation of pharmacist's intervention with the prescriber to suggest decreasing rivaroxaban dosage to $15 \mathrm{mg}$ DIE when eClcr is between $30-49 \mathrm{~mL} / \mathrm{min}$

Documentation of patient's absence of mechanical heart valve

Documentation of pharmacist's intervention with prescriber to suggest possibility of switching DOAC to VKA when patient has a mechanical heart valve

Documentation of pharmacist's intervention:

- With patient if adherence is suboptimal during 3 months (quantity of dispensed drug $\leq 90 \%$ or $\geq 110 \%$ of the required quantity according to prescription)

- With prescriber if adherence is suboptimal during 3 months (quantity of dispensed drug $\leq 80 \%$ or $\geq 120 \%$ of the required quantity according to prescription)

\begin{tabular}{|c|c|c|c|c|c|c|}
\hline v & $\sqrt{ }$ & & & & & $P$ \\
\hline$\checkmark$ & & & & & v & $P$ \\
\hline V & & & & & v & $\mathrm{P}$ \\
\hline \multirow[t]{3}{*}{$\sqrt{ }$} & & & & $\checkmark$ & & $\mathrm{P}$ \\
\hline & & & $\checkmark$ & & & $S$ \\
\hline & & & $\sqrt{ }$ & & & S \\
\hline$\checkmark$ & & & & & $v$ & $P$ \\
\hline \multirow[t]{2}{*}{$\checkmark$} & & & & & v & $P$ \\
\hline & & & & $\checkmark$ & & $\mathrm{P}$ \\
\hline$\checkmark$ & & & $\checkmark$ & & & $\mathrm{P}$ \\
\hline$\checkmark$ & & & $\checkmark$ & & & $\mathrm{P}$ \\
\hline \multirow[t]{6}{*}{$\checkmark$} & & & $\checkmark$ & & & $P$ \\
\hline & & $\sqrt{ }$ & & & & $\mathrm{O}$ \\
\hline & & & $\checkmark$ & & & $P$ \\
\hline & & & $\checkmark$ & & & $P$ \\
\hline & & & $\checkmark$ & & & $\mathrm{P}$ \\
\hline & & & $\checkmark$ & & & $P$ \\
\hline$\checkmark$ & & & $\checkmark$ & & & $P$ \\
\hline v & & & v & & & $P$ \\
\hline$\checkmark$ & & & & $\downarrow$ & & $P$ \\
\hline$\checkmark$ & & & & $\checkmark$ & & $P$ \\
\hline & & & & & & \\
\hline v & $\checkmark$ & & & & & $P$ \\
\hline$\checkmark$ & & & & $\checkmark$ & & P \\
\hline v & & & & $\sqrt{ }$ & & P \\
\hline$\checkmark$ & & & & $\sqrt{ }$ & & $P$ \\
\hline v & & & & $\checkmark$ & & $P$ \\
\hline$\checkmark$ & & & & $\sqrt{ }$ & & $P$ \\
\hline$\checkmark$ & & & $\checkmark$ & & & $P$ \\
\hline & & & & & & \\
\hline
\end{tabular}




\section{TABLE 1 Quality Indicators for Anticoagulation Therapy Management in Community Pharmacies (continued)}

\begin{tabular}{|c|c|c|c|c|c|c|c|}
\hline \multirow[b]{2}{*}{ Indicators } & \multicolumn{6}{|c|}{ Categories } & \multirow[b]{2}{*}{ స్ّ } \\
\hline & 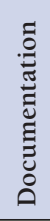 & 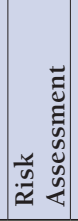 & 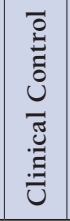 & 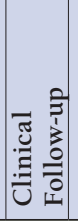 & 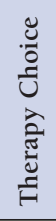 & 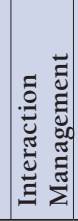 & \\
\hline \multicolumn{8}{|l|}{ Direct oral anticoagulant } \\
\hline Adherence $\geq 80 \%$ & & & & ل & & & $\mathrm{O}$ \\
\hline $\begin{array}{l}\text { Documentation of pharmacist's intervention to manage interactions between oral anticoagulants and } \\
\text { "azole" drugs }\end{array}$ & V & & & & & $\sqrt{ }$ & $\mathrm{P}$ \\
\hline Documentation of pharmacist's intervention to manage interactions between oral anticoagulants and ritonavir & $\sqrt{ }$ & & & & & $\sqrt{ }$ & $\mathrm{P}$ \\
\hline Documentation of pharmacist's intervention to manage interactions between oral anticoagulants and rifampin & $\sqrt{ }$ & & & & & $\sqrt{ }$ & $\mathrm{P}$ \\
\hline Documentation of pharmacist's intervention to manage interaction when patient is taking St. John's wort & $\sqrt{ }$ & & & & & $\sqrt{ }$ & $\mathrm{P}$ \\
\hline Documentation of presence or absence of side effects & $\sqrt{ }$ & & & $\sqrt{ }$ & & & $\mathrm{P}$ \\
\hline $\begin{array}{l}\text { Documentation of pharmacist's intervention to suggest possibility of switching DOAC to VKA when } \\
\text { eClcr } \leq 30 \mathrm{~mL} / \mathrm{min}\end{array}$ & $\checkmark$ & & & & $\checkmark$ & & $\mathrm{P}$ \\
\hline \multicolumn{8}{|c|}{$\begin{array}{l}\text { aType: } S=\text { structure (characteristics of service providers); } P=\text { process (steps in providing care); } O=\text { outcome (effect of care on health status); and Se=security (occurrence of } \\
\text { adverse events). } \\
\text { "This quality indicator could also be considered in "All oral anticoagulant therapy" section. } \\
\text { cAccording to official physician and pharmacy guidelines. } \\
\text { BID=twice a day; } C H A D S_{2}=\text { congestive heart failure, hypertension, age, diabetes and stroke; CHA2DS, VASC=congestive heart failure, hypertension, age, diabetes, stroke, } \\
\text { vascular disease and sex; DIE=once a day; DOAC=direct oral anticoagulant; eClcr=estimated creatinine clearance; HAS-BLED=hypertension, abnormal renal/liver } \\
\text { function, stroke, bleeding, labile INR, elderly and drugs/alcohol; HEMORR2HAGES=hepatic or renal disease, ethanol abuse, malignancy, older age, reduced platelet } \\
\text { count or function, rebleeding risk, hypertension, anemia, genetic factors, excessive fall risk and stroke; INR=international normalized ratio; LMWH=low-molecularweigh } \\
\text { heparin; TTR= time in therapeutic range; VKA=vitamin Kantagonist. }\end{array}$} \\
\hline
\end{tabular}

future research, it would be interesting to examine the possibility of adding quality indicators related to existing consensus guidelines that define the appropriate environment in anticoagulation clinics. ${ }^{63,64}$

Finally, quality indicators related to security are useful to monitor the occurrence of critical incidents (e.g., thromboembolic or bleeding event). ${ }^{20}$ Our set does not include any quality indicator of this type because such information cannot accurately be documented without using external sources of information (e.g., health records administrative databases). For example, if no bleeding event is reported by pharmacists, it would not be possible to confirm the information without talking to the patient or the prescribing physician or consulting the provincial hospitalization database. Cox et al. (2016) also concluded that the feasibility of assessing Canadian quality indicators for AF patients is limited because patients are followed in diverse outpatient settings. ${ }^{38}$

Our quality indicators were developed using a systematic approach based on an extensive literature review and a consensus approach using modified RAND appropriateness surveys. This method takes advantage of evidence-based information and expert judgment. We also performed a feasibility assessment to ensure that the quality indicators can be documented in the community pharmacy context.

\section{Limitations}

Certain limitations should be taken into account when using these quality indicators. Important quality indicators may be missing in our set, such as those that cannot be documented retrospectively using information from community pharmacy records or those that can only be verified using external sources of information (e.g., the quality indicator related to the percentage of patients with a known AF diagnosis who receive oral anticoagulation). Also, our expert panel consisted of a cardiologist, family physicians, and hospital and community pharmacists. Adding a nurse with expertise in anticoagulation management services and a representative of patients to the panel might have changed the results. Furthermore, the quality indicators are largely based on clinical guideline recommendations from Canada and Quebec and are specific to the community pharmacy context. They may not be directly applicable in other countries and other settings. Finally, it could be useful to validate the proposed quality indicators further with regard to reliability, convergent validity, predictive validity, and sensitivity to change.

Also, it must be borne in mind that not all clinical guideline recommendations can be adapted as quality indicators, depending on the level of evidence. ${ }^{19}$ In our study, the level of evidence (e.g., official physician and pharmacy guidelines ${ }^{5}$ ) supporting each quality indicator varies or is unknown but is 
minimally based on expert opinion. However, this is a first step toward developing reasonable quality indicators that can feasibly be applied. Our quality indicators will need to be updated as new guidelines are published and knowledge evolves. Quality indicators were developed with a conservative approach and can be adapted or modified when needed (e.g., shorter delay for requesting additional INR measurements, higher TTR target, and inclusion of other drug interactions related to VKAs).

\section{Conclusions}

A first set of quality indicators is now available and may be used to assess oral anticoagulant management in community pharmacies for AF patients. Health care professionals, decision makers, and researchers can use them to identify care gaps, develop relevant training programs and clinical tools, and conduct quality improvement programs. A pilot study aiming to assess the feasibility of implementing a quality improvement program for oral anticoagulant management by community pharmacists using these quality indicators will follow.

\section{Authors}

MYLĖNE CHARTRAND, BPharm, and LYNE LALONDE, BPharm, PhD, University of Montreal Hospital Research Center and Faculty of Pharmacy, University of Montreal, Quebec, Canada; LINE GUÉNETTE, BPharm, PhD, Faculty of Pharmacy, Université Laval, and Population Health and Optimal Health Practices Research Unit, Centre de recherche du Centre hospitalier universitaire de Québec-Université Laval, Quebec, Canada; DENIS BROUILLETTE, BPharm, DPH, Montreal Heart Institute, Quebec, Canada; STÉPHANE CÔTÉ, BPharm, DPC, Covapharm, St. Georges, Quebec, Canada; ROGER HUOT, MD, FRCPC, Montreal Heart Institute and Faculty of Medicine, University of Montreal, Quebec, Canada; JÉRÔME LANDRY, BPharm, Pharmacy Veronic Comtois, Gabrielle Landry \& Nathalie Ouellet pharmaciennes, Saint-Jeande-Matha, Quebec, Canada; JOSÉE MARTINEAU, BPharm, MSc, BCPS, Department of Pharmacy Services, Hôpital de la Cité-de-laSanté de Laval, Laval, Canada; SYLVIE PERREAULT, BPharm, PhD, Faculty of Pharmacy, University of Montreal, Quebec, Canada; BRIAN WHITE-GUAY, MD, CCMF, FRCPC, Faculty of Pharmacy and Faculty of Medicine, University of Montreal, and UMF-GMF Clinique de médecine familiale Notre-Dame, Montreal, Quebec, Canada; and DAVID WILLIAMSON, BPharm, PhD, BCPS, Faculty of Pharmacy, University of Montreal, and Department of Pharmacy Services and Research Center, Hôpital du Sacré-Coeur de Montréal, Quebec, Canada. ÉLISABETH MARTIN, MSc, and MARIEMIREILLE GAGNON, MSc, University of Montreal Hospital Research Center, Quebec, Canada.

AUTHOR CORRESPONDENCE: Lyne Lalonde, BPharm, PhD, Faculty of Pharmacy, University of Montreal, P.O. Box 6128, Centre-ville Station, Montreal, Quebec, Canada H3C 3J7. Tel.: 514.343.6111,ext. 5315; E-mail:lyne.lalonde@umontreal.ca.

\section{DISCLOSURES}

This research was supported by the Réseau Québécois de recherche sur le médicament (RQRM); the Blueprint for Pharmacy in collaboration with Pfizer Canada; and the Cercle du Doyen of the Faculty of Pharmacy, University of Montreal. The study sponsors were not involved in the study design, data collection, data interpretation, the writing of the article, or the decision to submit the report for publication.

Chartrand received a scholarship from the Fonds de Recherche du Québec en Santé (FRQ-S), the Réseau Québécois de recherche sur l'usage des médicaments with Pfizer, and the Faculty of Pharmacy, University of Montreal. Guénette holds a Junior-1 Clinician Researcher Award from the FRQ-S in partnership with the Société québécoise d'hypertension artérielle. Williamson holds a Junior-1 Career Award from the FRQ-S. Côté reported being a medical speaker for Bayer, Boehringer Ingelheim Canada, and Pfizer Canada. The other authors reported no conflicts of interest.

Study concept and design were contributed by Lalonde, Chartrand, and Martin. Chartrand, Martin, and Lalonde collected the data, along with Brouillette, Côté, Huot, Landry, Martineau, Perreault, Williamson, and White-Guay. Data interpretation was performed by Chartrand, Gagnon, and Lalonde, along with Guénette and Martin. The manuscript was primarily written by Chartrand, along with Guénette and Lalonde, and revised by Chartrand, Guénette, and Lalonde, along with the other authors.

A portion of this study's results was presented at the 4th RQRM Annual Meeting on September 22-23, 2014, in Orford, Quebec, Canada, in the form of an abstract, which was published in the Journal of Population Therapeutics and Clinical Pharmacology, 2014;21(2):e312.

\section{ACKNOWLEDGMENTS}

The authors thank Patrice Dupont (librarian) for helping to elaborate the search strategy, participating community pharmacists for the feasibility assessment (phase 3), Eveline Hudon for participating in phase 2 as an expert, and Nancy Presse for reviewing the manuscript.

\section{REFERENCES}

1. Heeringa J, van der Kuip DA, Hofman A, et al. Prevalence, incidence and lifetime risk of atrial fibrillation: the Rotterdam study. Eur Heart J. 2006;27(8):949-53

2. Ball J, Carrington MJ, McMurray JJ, Stewart S. Atrial fibrillation: profile and burden of an evolving epidemic in the 21st century. Int J Cardiol. 2013;167(5):1807-24.

3. Hart RG, Pearce LA, Aguilar MI. Meta-analysis: antithrombotic therapy to prevent stroke in patients who have nonvalvular atrial fibrillation. Ann Intern Med. 2007;146(12):857-67.

4. Ruff CT, Giugliano RP, Braunwald E, et al. Comparison of the efficacy and safety of new oral anticoagulants with warfarin in patients with atrial fibrillation: a meta-analysis of randomised trials. Lancet. 2014;383(9921):955-62.

5. Collège des médecins du Québec (CMQ), Ordre des pharmaciens du Québec (OPQ). Lignes directrices-Anticoagulothérapie en milieu ambulatoire. 2005. Available at: http://www.opq.org/cms/Media/809_38_fr-CA_0_ ld_anticoagulotherapie_pharm.pdf. Accessed March 1, 2018.

6. Macle L, Cairns J, Leblanc K, et al. 2016 focused update of the Canadian Cardiovascular Society Guidelines for the management of atrial fibrillation. Can J Cardiol. 2016;32(10):1170-85.

7. You JJ, Singer DE, Howard PA, et al. Antithrombotic therapy for atrial fibrillation: Antithrombotic Therapy and Prevention of Thrombosis, 9th ed: American College of Chest Physicians Evidence-Based Clinical Practice Guidelines. Chest. 2012;141(2 Suppl):e531S-75S.

8. Roskell NS, Samuel M, Noack H, Monz BU. Major bleeding in patients with atrial fibrillation receiving vitamin $\mathrm{K}$ antagonists: a systematic review of randomized and observational studies. Europace. 2013;15(6):787-97. 
9. Lalonde L, Maheu A, Chartrand M, Martin É, Gagnon M-M. Enquête sur les services cliniques spécialisés en pharmacie communautaire réalisée dans le cadre du Réseau STAT. 2015. Available at: http://reseaustat.ca/fr/viewbibliotheque.php?bibliId=65. Accessed March 1, 2018.

10. Amruso NA. Ability of clinical pharmacists in a community pharmacy setting to manage anticoagulation therapy. J Am Pharm Assoc (2003). 2004:44(4):467-71.

11. Harper P, McMichael I, Griffiths D, Harper J, Hill C. The community pharmacy-based anticoagulation management service achieves a consistently high standard of anticoagulant care. N Z Med J. 2015;128(1422):31-41.

12. Harrison J, Shaw JP, Harrison JE. Anticoagulation management by community pharmacists in New Zealand: an evaluation of a collaborative model in primary care. Int J Pharm Pract. 2015;23(3):173-81.

13. Jackson SL, Peterson GM, Bereznicki LR, Misan GM, Jupe DM, Vial JH. Improving the outcomes of anticoagulation in rural Australia: an evaluation of pharmacist-assisted monitoring of warfarin therapy. J Clin Pharm Ther. 2005;30(4):345-53

14. Knowlton CH, Thomas OV, Williamson A, et al. Establishing community pharmacy-based anticoagulation education and monitoring programs. J Am Pharm Assoc (Wash). 1999;39(3):368-74.

15. Côté S. Innovation: une clinique réseau d'anticoagulothérapie dans votre pharmacie. Pharmactuel. 2010;43(4):256-63.

16. Wilson SJ-A, MacLellan E, Cox JL, et al. A pilot study evaluating the feasibility of monitoring oral anticoagulant therapy with point-of-care testing in a community pharmacy. Can J Hosp Pharm. 2004;57(3):158-64.

17. Coleman B, Martin C, Barber N, Patterson D. An evaluation of the safety and acceptability of an anticoagulation clinic in a community pharmacy setting-a pilot study. Pharm J. 2004;273(7328):822-24.

18. Shimizu T, Momose Y, Ogawa R, Takahashi M, Echizen H. Impact of pharmacists' audit on improving the quality of prescription of dabigatran etexilate methanesulfonate: a retrospective study. J Pharm Health Care Sci. 2017;3:4.

19. Campbell SM, Braspenning J, Hutchinson A, Marshall M. Research methods used in developing and applying quality indicators in primary care. Qual Saf Health Care. 2002;11(4):358-64.

20. Institut national d'excellence en santé et en services sociaux (INESSS). Des indicateurs de qualité à l'intention des professionnels et des gestionnaires des services de première ligne. Rapport rédigé par Marie-Dominique Beaulieu, Marie-Pascale Pomey, Brigitte Côté, Claudio Del Grande, Monia Ghorbel, Phuong Hua et Éric Tremblay. ETMIS. 2012;8(12):1-68.

21. Mainz J. Defining and classifying clinical indicators for quality improvement. Int J Qual Health Care. 2003;15(6):523-30.

22. Donabedian A. Evaluating the quality of medical care. Milbank Mem Fund Q. 1966;44(3 Suppl):166-206.

23. Donabedian A. The quality of care. How can it be assessed? JAMA. 1988;260(12):1743-48.

24. Nau DP. Measuring pharmacy quality. J Am Pharm Assoc (2003). 2009;49(2):154-63

25. Beauchesne M-F, Bertrand CC, Noël A, et al. Élaboration et évaluation d'indicateurs de la qualité des soins pharmaceutiques en médecine interne au CHUS. Pharmactuel. 2013;46(3):184-91.

26. Canadian Cardiovascular Society. Quality indicators for atrial fibrillation/flutter. September 4, 2013. Available at: https://www.ccs.ca/images/ Health_Policy/Quality-Project/Indicator_AF.pdf. Accessed March 1, 2018.

27. Cheng EM, Fung CH. Quality indicators for the care of stroke and atrial fibrillation in vulnerable elders. J Am Geriatr Soc. 2007;55(Suppl 2):S431-37.

28. Kerr EA, Steven M. Asch, Eric G. Hamilton, McGlynn. EA, eds. Quality of Care for Cardiopulmonary Conditions: A Review of the Literature and Quality Indicators. Santa Monica, CA: RAND Corporation; 2000. Available at: http://www.rand.org/pubs/monograph_reports/MR1282.html. Accessed March 1, 2018.
29. NHS National Patient Safety Agency. Anticoagulation for atrial fibrillation. A simple overview to support the commissioning of quality services. NHS Improvement-Heart. April 2011. Available at: https://www.slideshare net/NHSImprovement/anticoagulation-for-atrial-fibrilation-a-simple-overview-to-support-the-commissioning-of-quality-services. Accessed March 1, 2018.

30. Rose AJ, Berlowitz DR, Frayne SM, Hylek EM. Measuring quality of oral anticoagulation care: extending quality measurement to a new field. Jt Comm J Qual Patient Saf. 2009;35(3):146-55.

31. Rose AJ, Hylek EM, Berlowitz DR, Ash AS, Reisman JI, Ozonoff A. Prompt repeat testing after out-of-range INR values: a quality indicator for anticoagulation care. Circ Cardiovasc Qual Outcomes. 2011;4(3):276-82.

32. Rose AJ, Hylek EM, Ozonoff A, Ash AS, Reisman JI, Berlowitz DR. Risk-adjusted percent time in therapeutic range as a quality indicator for outpatient oral anticoagulation: results of the Veterans Affairs Study to Improve Anticoagulation (VARIA). Circ Cardiovasc Qual Outcomes 2011;4(1):22-29.

33. Abrahamyan L, Boom N, Donovan LR, Tu JV; Canadian Cardiovascular Society Quality Indicators Steering Committee. An international environmental scan of quality indicators for cardiovascular care. Can J Cardiol. 2012;28(1):110-18.

34. Pharmacy Quality Alliance. PQA performance measures. 2017. Available at: http://pqaalliance.org/measures/default.asp. Accessed March 1, 2018.

35. Agency for Healthcare Research and Quality. National Quality Measures Clearinghouse. 2017. Available at: https://www.qualitymeasures.ahrq.gov/ browse/domain. Accessed March 1, 2018.

36. Kaatz S. Determinants and measures of quality in oral anticoagulation therapy. J Thromb Thrombolysis. 2008;25(1):61-66.

37. Witt DM. Quality measures and benchmarking for warfarin therapy. J Thromb Thrombolysis. 2011;31(3):242-48.

38. Cox JL, Dai S, Gong Y, et al. The development and feasibility assessment of Canadian quality indicators for atrial fibrillation. Can J Cardiol. 2016;32(12):1566-69.

39. American Heart Association/Heart Rythm Society. AFIB atrial fibrillation fact sheet. 2016. Available at: https://www.heart.org/idc/groups/ heart-public/@private/@wcm/@hcm/@gwtg/documents/downloadable/ ucm_451183.pdf. Accessed March 1, 2018.

40. National Institute for Health and Care Excellence. Standards and indicators. Quality and outcomes framework. Atrial fibrillation. 2014. Available at: https://www.nice.org.uk/standards-and-indicators/index/QOF/All. Accessed March 1, 2018.

41. Barnes GD, Kline-Rogers E. Engaging with quality improvement in anticoagulation management. J Thromb Thrombolysis. 2015;39(3):403-09.

42. Eymin G, Jaffer AK. Evidence behind quality of care measures for venous thromboembolism and atrial fibrillation. J Thromb Thrombolysis. 2014;37(2):87-96

43. McBane S, Trewet CB, Havican SN, et al. Tenets for developing quality measures for ambulatory clinical pharmacy services. Pharmacotherapy. 2011;31(7):115e-34e.

44. Wenger NS, Roth CP, Shekelle P; ACOVE Investigators. Introduction to the assessing care of vulnerable elders-3 quality indicator measurement set. J Am Geriatr Soc. 2007;55(Suppl 2):S247-52.

45. Poller L, Jespersen J, Cowan C, Baglin T, George J, Ibrahim SA. Application of the UK NHS Improvement Anticoagulation Commissioning Support Document for 'safety indicators' in atrial fibrillation. Results of the European Action on Anticoagulation study. J Clin Pathol. 2012;65(5):452-56.

46. Heidenreich PA, Solis P, Estes NA 3rd, et al. 2016 ACC/AHA Clinical Performance and Quality Measures for Adults with Atrial Fibrillation or Atrial Flutter: a report of the American College of Cardiology/American Heart Association Task Force on Performance Measures. J Am Coll Cardiol. 2016;68(5):525-68. 
47. Lavoie K, Turgeon M-H, Brais C, et al. Inappropriate dosing of direct oral anticoagulants in patients with atrial fibrillation. J Atr Fibrillation. 2016/17;9(4):6-10.

48. De Bie J, Kijlstra NB, Daemen BJ, Bouvy ML. The development of quality indicators for community pharmacy care. BMJ Qual Saf. 2011;20(8):666-71.

49. Teichert M, Schoenmakers T, Kylstra N, et al. Quality indicators for pharmaceutical care: a comprehensive set with national scores for Dutch community pharmacies. Int J Clin Pharm. 2016;38(4):870-79.

50. Schoenmakers TW, Teichert M, Braspenning J, Vunderink L, De Smet PA, Wensing M. Evaluation of quality indicators for Dutch community pharmacies using a comprehensive assessment framework. J Manag Care Spec Pharm. 2015;21(2):144-52. Available at: https://www.jmcp.org/ doi/10.18553/jmcp.2015.21.2.144.

51. Fitch K, Bernstein SJ, Aguilar MD, et al. The RAND/UCLA Appropriateness Method User's Manual. Santa Monica, CA: RAND Corporation; 2001.

52. Skanes AC, Healey JS, Cairns JA, et al. Focused 2012 update of the Canadian Cardiovascular Society Atrial Fibrillation Guidelines: recommendations for stroke prevention and rate/rhythm control. Can J Cardiol. 2012;28(2):125-36.

53. American Heart Association/American Stroke Association. AFIB atrial fibrillation fact sheet. 2014. Available at: https://www.heart.org/idc/groups/ heart-public/@private/@wcm/@hcm/@gwtg/documents/downloadable/ ucm_451183.pdf. Accessed March 1, 2018.

54. Estes NA 3rd, Halperin JL, Calkins H, et al. ACC/AHA/Physician Consortium 2008 clinical performance measures for adults with nonvalvular atrial fibrillation or atrial flutter: a report of the American College of Cardiology/American Heart Association Task Force on Performance Measures and the Physician Consortium for Performance Improvement (Writing Committee to Develop Clinical Performance Measures for Atrial Fibrillation): developed in collaboration with the Heart Rhythm Society. Circulation. 2008;117(8):1101-20.
55. NHS Employers. Quality and outcomes framework guidance for GMS contract 2013/14. Pages 35-38. 2013. Available at: http://content.digital.nhs. uk/media/14018/QOF-Guidance-GMS-Contract-2013-14/pdf/QOF_guidance_GMS_contract_2013_14.pdf. Accessed March 13, 2018.

56. Cerqueira Santos S, Boaventura TC, Rocha KS, de Oliveira Filho AD, Onozato T, de Lyra DP Jr. Can we document the practice of dispensing? A systematic review. J Clin Pharm Ther. 2016;41(6):634-44.

57. Floor-Schreudering A, De Smet PA, Buurma H, Egberts AC, Bouvy ML. Documentation quality in community pharmacy: completeness of electronic patient records after patients' first visits. Ann Pharmacother. 2009;43(11):1787-94.

58. Guirguis LM, Lee S. Patient assessment and documentation integrated in community practice: chat, check, and chart. J Am Pharm Assoc (2003). 2012;52(6):e241-51

59. Leung V, Tharmalingam S, Cooper J, Charlebois M. Canadian community pharmacists' use of digital health technologies in practice. Can Pharm J (Ott). 2016;149(1):38-45.

60. Westerling AM, Haikala V, Airaksinen M. The role of information technology in the development of community pharmacy services: visions and strategic views of international experts. Res Social Adm Pharm. 2011;7(4):430-37.

61. Ageno W, Gallus AS, Wittkowsky A, et al. Oral anticoagulant therapy: Antithrombotic Therapy and Prevention of Thrombosis, 9th ed: American College of Chest Physicians Evidence-Based Clinical Practice Guidelines. Chest. 2012;141(2 Suppl):e44S-88S.

62. Andrade SE, Kahler KH, Frech F, Chan KA. Methods for evaluation of medication adherence and persistence using automated databases. Pharmacoepidemiol Drug Saf. 2006;15(8):565-74.

63. Ansell JE, Buttaro ML, Thomas OV, Knowlton CH. Consensus guidelines for coordinated outpatient oral anticoagulation therapy management. Anticoagulation Guidelines Task Force. Ann Pharmacother. 1997;31(5):604-15.

64. Garcia DA, Witt DM, Hylek E, et al. Delivery of optimized anticoagulant therapy: consensus statement from the Anticoagulation Forum. Ann Pharmacother. 2008;42(7):979-88. 